\title{
Induction of Protective Immunity against Schistosoma mansoni Infection by Antigens Purified from PIII, a Fraction of Adult Worm, Associated to the Downregulation of Granuloma Formation
}

\author{
Shauma Gustavson, Sérgio Costa Oliveira, José Bento Alves*, Alfredo \\ Miranda Goes ${ }^{+}$
}

\begin{abstract}
Departamento de Bioquímica e Imunologia *Departamento de Morfologia, ICB, Universidade Federal de Minas Gerais, Caixa Postal 486, 30161-970 Belo Horizonte, MG, Brasil
\end{abstract}

\begin{abstract}
This study was performed in order to define Schistosoma mansoni antigens able to function as modulator agents in BALB/c mice granulomatous hypersensitivity to parasite egg. The antigens $P-24, P-35$ and $P-97$ were purified by affinity chromatography from a fraction of $\mathrm{S}$. mansoni adult worm antigenic preparation, denominated PIII, involved in the inhibition of granulomatous response to eggs. Immunization of mice with these antigens, in the presence of Corynebacterium parvum and $\mathrm{Al}(\mathrm{OH})_{3}$ as adjuvant, induced a significant protection degree against challenge infection, as observed by the decrease on worm burden recovered from portal system. In vitro blastogenesis assays revealed that purified antigens were able to induce significant proliferation of spleen cells from $\mathrm{S}$. mansoni-infected mice. This protection was correlated to significant decrease in granuloma size induced by PIII. From these results, we concluded that PIII preparation contains antigens capable of mediating protective anti-parasite immunity and down-regulating granulomatous hypersensitivity to S. mansoni eggs.
\end{abstract}

Key words: Schistosoma mansoni - granuloma modulation - adult worm - immunity - vaccine

One of the features of schistosomiasis immunobiology is the gradual and spontaneous reduction in the size of granulomatous inflammation around the continuously incoming eggs. This phenomenon, termed immunomodulation (Andrade \& Warren 1964), has been the subject of numerous studies showing the participation of cellular as well as subcellular mechanisms in regulation of granulomatous process (Goes et al. 1991, Cheever et al. 1992, Rezende et al. 1998).

Therefore, the identification of Schistosoma mansoni antigens and an assessment of their role in host-parasite interaction, notably in the prevention or decrease in granuloma size by immunization procedure, are essential for the development of an anti-schistosome vaccine (Bergquist 1990). The future progress in this field depends on the

\footnotetext{
This work received financial assistance from Conselho Nacional de Pesquisa (CNPq/PIBIC), Pró-Reitoria de Pesquisa da Universidade Federal de Minas Gerais (PRPq/UFMG) and Fundação de Amparo à Pesquisa de Minas Gerais (Fapemig/Probic).

${ }^{+}$Corresponding author. Fax: +55-31-441.5963. E-mail: goes@mono.icb.ufmg.br

Received 4 May 1998

Accepted 31 August 1998
}

understanding of the complex immunoregulatory events that modulate the evolution of granulomatous hypersensitivity to $S$. mansoni eggs and the basis of protective immunity in man (Butterworth 1992). Several experimental approaches have been carried out to identify S. mansoni antigens that elicit $\mathrm{T}$ cell proliferation and granuloma formation, including parasite antigens purified by conventional purification techniques (Carter \& Colley 1979, Payares et al. 1985, Harn et al. 1989, Lukacs \& Boros 1992), by affinity chromatography with monoclonal antibodies (Dissous et al. 1982, Harn et al. 1985, Smith \& Clegg 1985, Hsu et al. 1986, Hirsch et al. 1997) or by recombinant DNA technology (Boulanger et al. 1991, Jeffs et al. 1991). Conflicting results were reported by different laboratories, notably respect to the type of antigens which yield the highest levels of resistance, a single or cocktail antigen capable of giving significantly increase of resistance, and whether a vaccine would aggravate or ameliorate the granulomatous egg pathology (Warren et al. 1967). Our laboratory has produced PIII, an anionic fraction from soluble adult worm antigen preparation (SWAP), able to induce high levels of proliferation and low in vitro granuloma reactions by human peripheral blood mononuclear cells from chronic schistosomiasis patients, besides smaller in vivo granuloma formation in mice (Hirsch \& Goes 1996). In this paper, 
we have purified PIII components and determined their capacity to induce protection against experimental infection and to elicit spleen cells proliferation.

\section{MATERIALS AND METHODS}

Mice and parasites - Adult female BALB/c mice purchased from Centro de Bioterismo, ICB, UFMG, Belo Horizonte, MG, Brazil, and maintained under standard laboratory care, were used throughout this study. Cercariae of S. mansoni were obtained from Biomphalaria glabrata snails, previously infected with miracidia of the L.E. strain, from Belo Horizonte, Brazil. Anesthetized mice (10/group) were exposed to cercariae on the abdomen, using the ring method of Smithers and Terry (1965). Vaccinated and control mice challenged with cercariae were perfused eight weeks after exposure (Smithers \& Terry 1965). The protective immunity of each group was evaluated by comparing the recovery of worms from immunized and control mice.

Antigens and mitogens - Antigenic preparations were obtained from schistosome eggs (SEA), adult worms (SWAP) and cercariae (CAP), prepared as soluble supernatant fluids from buffered saline homogenates of the respective life-cycle stages (Goes et al. 1989). PIII was obtained from SWAP on FPLC system (Pharmacia, Upsala, Sweden) using Q-Sepharose anion-exchange chromatography $(5 \mathrm{~mm}$ x $90 \mathrm{~mm}$ glass columns packed with Q-Sepharose; bead size distribution: 45-165 mm; Pharmacia), as previously described by Hirsch and Goes (1996). PIII components (P-24, P-35, P-97) were purified by affinity chromatography. Other antigens used were Concanavalin A (Con-A, Sigma, St. Louis, MO, USA) and bovine serum albumin (BSA, Sigma). These materials were used based on their protein content to give maximum response in blastogenesis assay $(25 \mathrm{mg} / \mathrm{ml})$. All stimulants were sterilized by filtration and stored at $-70^{\circ} \mathrm{C}$.

Sodium dodecylsulfate polyacrylamide gel electrophoresis (SDS-PAGE) and Western blot - PIII, affinity purified PIII components and SWAP were subjected to discontinuous electrophoresis using $10 \%$ SDS-polyacrylamide gels, under reducing conditions (Laemmli 1970). Separated proteins were electrophorectically transferred to nitrocellulose paper (Towbin et al. 1979) and then reacted with rabbit sera against SWAP and PIII (Hirsch et al. 1997).

Production of specific antisera - P-24, P-35 and P-97 were excised from SDS-PAGE and used as immunogens to produce specific antisera. For each immunization, Coomassie blue-stained proteins were cut from two to three gels, washed with phos- phate buffer saline (PBS), and homogenized with $0.5 \mathrm{ml}$ of PBS. Antisera were obtained from rabbits immunized by i.m. injections of sample emulsified with Complete Freund Adjuvant at a 1:1 ratio, and boosted twice, at 2-week intervals, with identical antigen amounts but with Incomplete Freund Adjuvant. Specific rabbit antibodies were coupled to cyanogen bromide-activated Sepharose4B, and P-24, P-35 and P-97 components were purified as described by Goding (1986).

Immunization of mice with PIII and their purified components - Groups of five BALB/c mice were immunized by s.c. injections of $10 \mathrm{mg}$ of PIII, $\mathrm{P}-24, \mathrm{P}-35$ or P-97 preparations, in the presence of $100 \mathrm{mg}$ of Corynebacterium parvum and $1 \mathrm{mg}$ of aluminium hydroxide $\left[\mathrm{Al}(\mathrm{OH})_{3}\right]$ as adjuvant. Animals were boosted twice, at 2-week intervals, with identical amounts of antigen, but the last injection was done by i.p. without adjuvant.

Measurement of hepatic granuloma formation - PIII immunized and infected mice were killed eight weeks after challenge infection. Livers were removed and fixed with $4 \%$ paraformaldehyde in phosphate buffer. Histologic sections were stained with hematoxilin/eosin or Heidenhein's azan (Hirata et al. 1993). Only lesions with a single welldefined egg nidus were measured. Results were expressed as the average area $\left(\mathrm{mm}^{2} \pm\right.$ S.D. $)$ calculated from 30 to 50 granulomas.

Spleen cell preparation - Single cell suspensions, which had been prepared from spleens of normal, infected or PIII and PIII-purified components immunized mice, were treated with Trisammonium chloride $\mathrm{pH} 7.2$ to erythrocyte lysis, washed and counted. Spleen cells were resuspended in culture medium (RPMI 1640 with $20 \%$ fetal bovine serum, $1.6 \%$ L-glutamine, $300 \mathrm{~m} / \mathrm{ml}$ of penicillin, $0.6 \mathrm{mg} / \mathrm{ml}$ of streptomycin and 0.05 $\mathrm{mg} / \mathrm{ml}$ of gentamycin).

Cellular proliferation assays - Spleen cell proliferation assays were done in response to Con-A, P-24, P-35, P-97 and other S. mansoni antigens (SWAP, SEA and CAP). Briefly, $7.0 \times 10^{5}$ spleen cells were cultured in $200 \mathrm{ml}$ of culture medium, in 96-well flat-bottom plates. Every experiment was set up in triplicate. Cultures were stimulated with $25 \mathrm{mg} / \mathrm{ml}$ of each antigen (plus control without antigen) and maintained at $37^{\circ} \mathrm{C}$ in $5 \% \mathrm{CO}_{2}$ incubator for three days. For the last $18 \mathrm{hr}$ of incubation, cultures were pulsed with $0.5 \mathrm{mCi} /$ well of tritiated thymidine (specific activity, $37 \mathrm{Ci} / \mathrm{ml}$; New England Nuclear, Boston, MA, USA). Cells were harvested for scintillation counting and data were calculated as mean \pm S.E. of cpm values.

Statistics - Data were analyzed statistically by the Student's $t$-test with the level of significance set at $P<0.05$. 


\section{RESULTS}

Immunization of mice with PIII and its effect on hepatic granuloma formation - Immunization of mice with PIII resulted in a significant reduction in hepatic granuloma size after challenge infection (Fig. 1). The foci in livers of infected mice were more numerous and frequently very large (Fig. 2A), extending up to $109 \times 10^{3} \mathrm{~mm}^{2}$ (Fig. 1). Hepatic granulomas of PIII vaccinated group presented small foci and the size was reduced to $62 \mathrm{x}$ $10^{3} \mathrm{~mm}^{2}$ (Figs 1, 2B). The percentage of granuloma reduction in these animals was $43 \%$, significantly different from the controls $(P<0.05)$.

Immunoaffinity purification of PIII components - Immunoaffinity chromatography was used to purify antigens from PIII, prepared in the absence of protease inhibitors. For that assay, specific rabbit antibodies against electroforeticaly isolated PIII components were coupled to Sepharose-4B. SDSPAGE and Western blot analysis demonstrated that these purified antigens present M.W. of $24 \mathrm{kDa}$ (P-24), $35 \mathrm{kDa}(\mathrm{P}-35), 44 \mathrm{kDa}(\mathrm{P}-44)$, and $97 \mathrm{kDa}$ (P-97) (data not shown).

In vitro stimulatory capacity of purified PIII components - Splenic cells from infected and PIII and purified components immunized mice were tested for in vitro antigen-specific proliferation. Results (Fig. 3) demonstrated considerable varia-

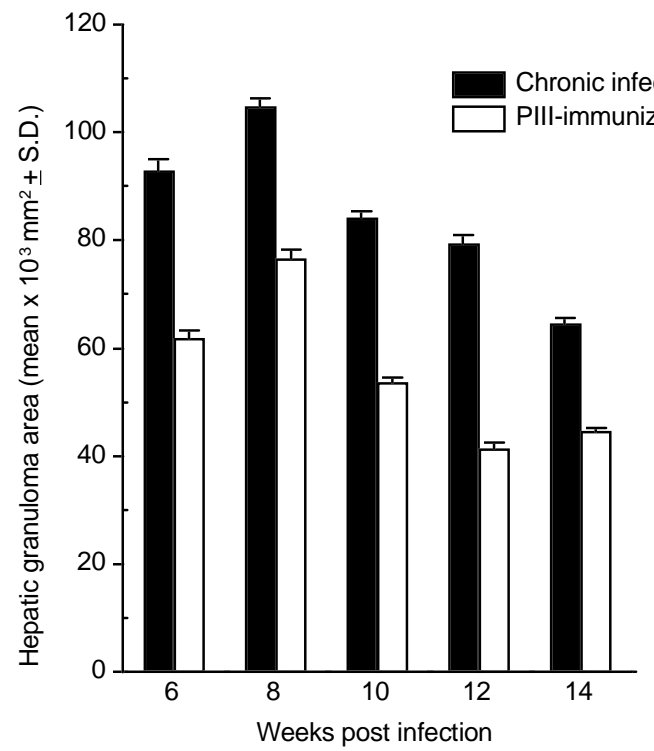

Fig. 1: kinetics of hepatic granuloma size distribution in either chronic infection or after challenge infection in PIII immunized $\mathrm{BALB} / \mathrm{c}$ mice. Animals were infected, as described in the Materials and Methods, sacrified 6 to 14 weeks after infection, and histological analysis of livers HE stained sections were performed. The size of each granuloma surrounding mature egg was measured with the aid of an ocular micrometer. Results average of 30 granulomas, $\left(\mathrm{mm}^{2} \pm\right.$ S.D. $)$ from three animals per group ( $\mathrm{n}=90 /$ group).

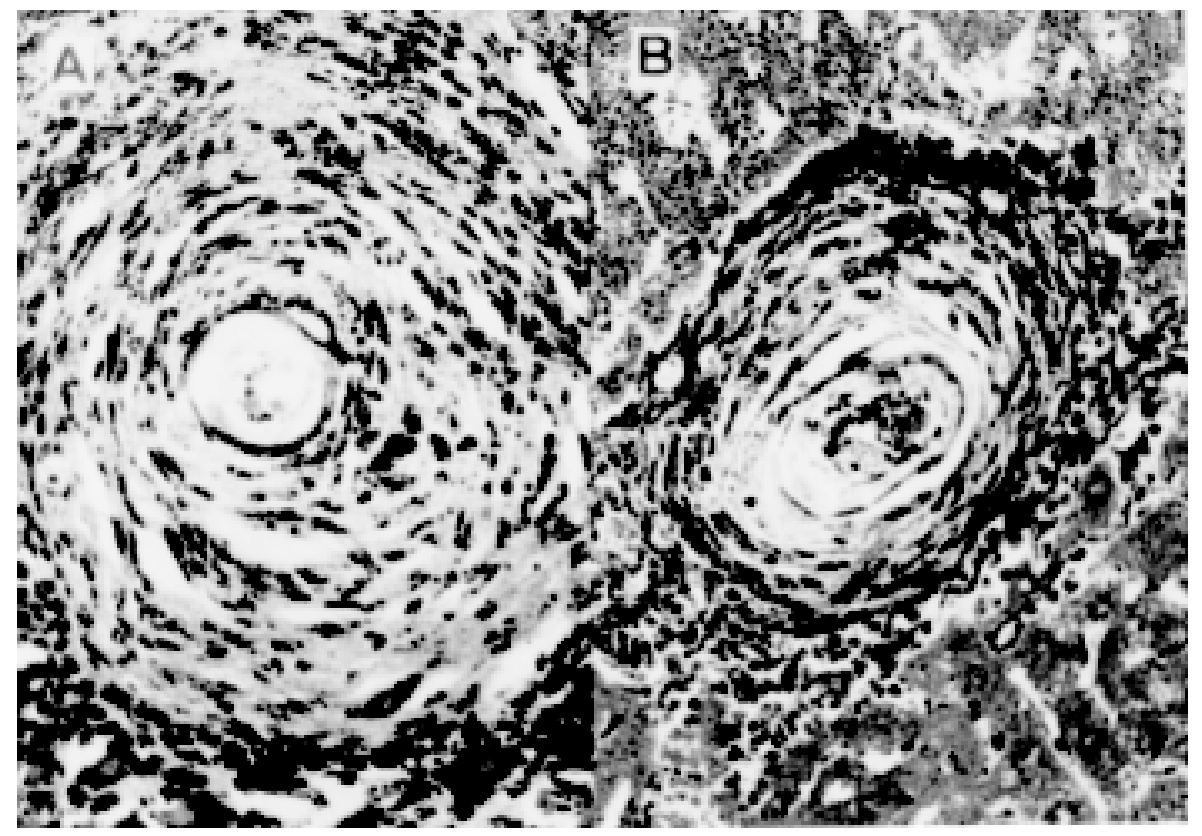

Fig. 2: hepatic granuloma photomicrographs (x 250) of BALB/c mice, eight weeks after challenge infection, in either non-immunized (A) or PIII immunized ones (B). Histological sections were stained by Heidenhein's azan procedure. 
tion in the degree of proliferative responses, between the antigens tested. Crude SWAP promoted strong responses of splenic cells from infected and immunized mice. In the same assay, spleen cells were highly stimulated by P-35 and P-24 (Fig. 3B). In additional experiments, we observed that P-97 was able to induce cell proliferation (Fig. 3A) as well as to detect other purified antigens (Fig. 3B).

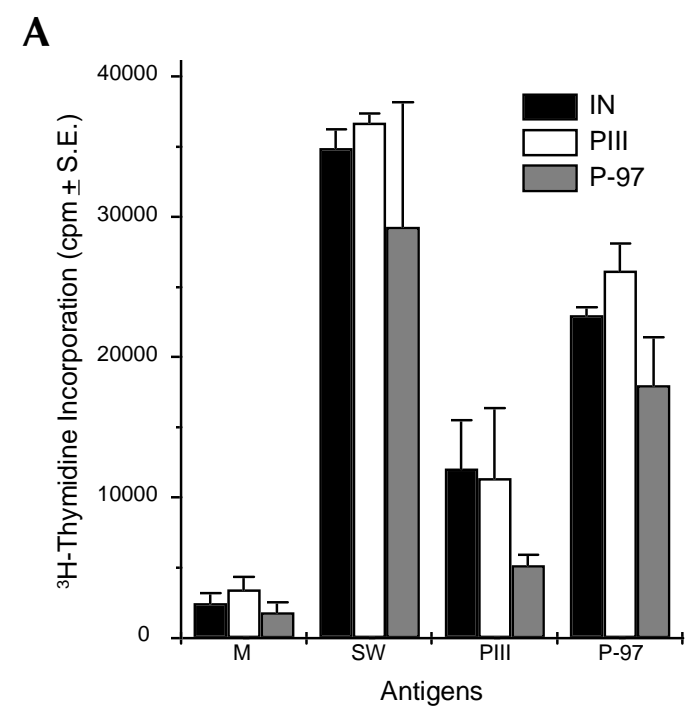

B

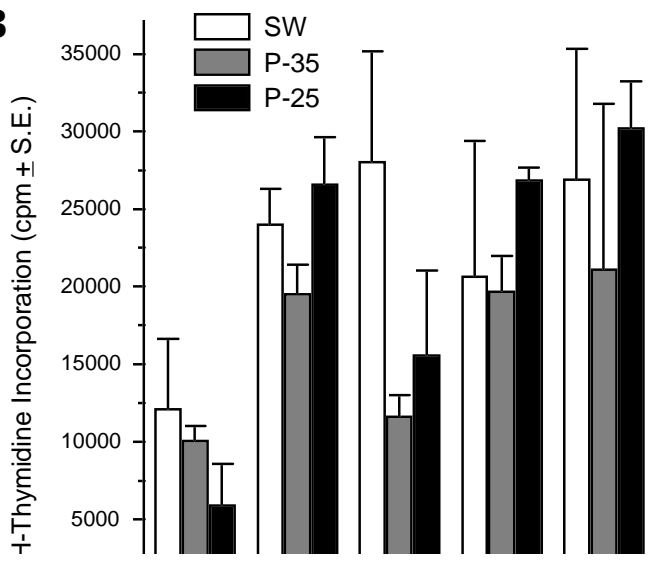

Fig. 3: effect of P-24, P-35 and P-97 on cellular proliferation. Spleen cells were collected from BALB/c mice infected (IN; A) or immunized with SWAP (SW; A and B), PIII (A, B), P97(A), P-35 (B) or P-24 (B), eight weeks after challenge infection. Cells were incubated with $25 \mathrm{mg} / \mathrm{ml}$ of these antigens, for five days. Cultures were pulsed for the final $18 \mathrm{hr}$ with $0.5 \mathrm{mCi}$ of tritiated thymidine and incorporated radioactivity was determined. Data are reported as mean of $\mathrm{cpm} \pm$ S.E. for $\mathrm{N}=5$ for each experimental group. Controls: cells in medium $=2.505 \pm$ $0.700 \mathrm{cpm}$; Con-A $=26.321 \pm 2.445 \mathrm{cpm}$.
Immunization of mice with $P-24$ and $P-35$, and its effect on a subsequent infection with $S$. mansoni cercariae - The protective effect of P-24 and P-35 was additionally investigated. As shown on Fig. 4, the number of worms recovered eight weeks after challenge infection of immunized mice was significantly reduced when compared to that observed in adjuvant-immunized or not immunized control animals. The immunization with P-24 and P-35 established a protection of $55 \%$ and $67 \%$, respectively.

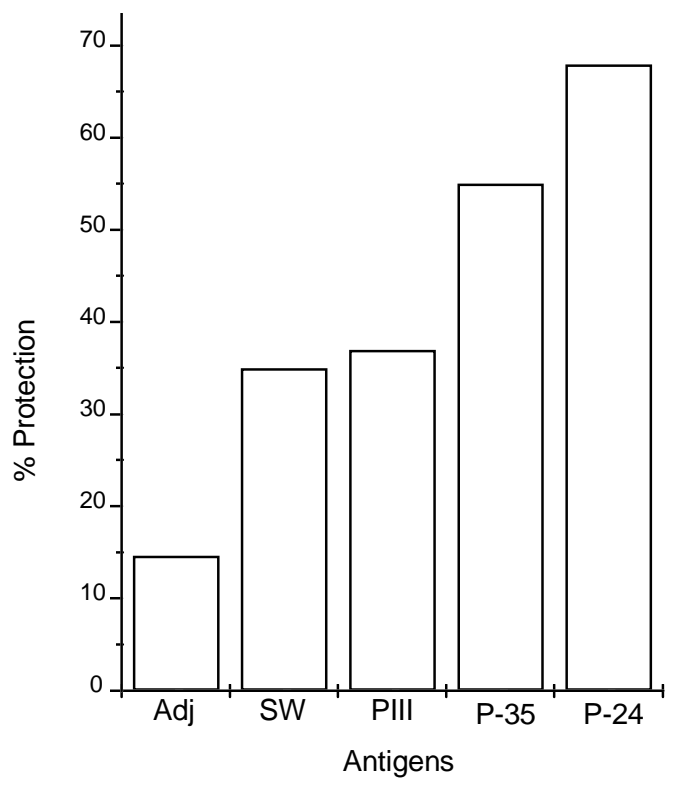

Fig. 4: protective effect of P-24 and P-35. BALB/c mice were immunized with $10 \mathrm{mg}$ of each antigen, in presence of Corynebacterium parvum and $\mathrm{Al}(\mathrm{OH})_{3}$, as described in Materials and Methods. Worm burden was determined by perfusion of portal system at eight weeks after challenge infection, in 5 mice/group. $\%$ Protection $=100$ - experimental/control $\mathrm{x} 100$.

\section{DISCUSSION}

In the present work we described the characterization and functional properties of P-25, P-35 and P-97, purified from PIII, an antigenic protein fraction obtained from $S$. mansoni adult worms, which fails to induce vigorous granulomatous hypersensitivity to eggs on liver, but also causes protection against a challenge infection in mice after (s.c.) immunization (Hirsch et al. 1997). Our results demonstrated that mice vaccinated with PIII can alter the kinetics of granulomatous hypersensitivity reaction to parasite eggs. Vaccinated mice developed hepatic granulomas lesser than unvaccinated controls. 
These findings are in accordance to previous results reported by Hirsch and Goes (1996), using an in vitro granuloma formation system, and by Wynn et al. (1994) and Hirsch et al. (1997) in mice in vivo model. The ability of PIII to suppress egginduced hepatic granulomatous responses indicates the presence, within adult worm antigens, of several molecules that might play a role in the modulation of granulomatous hypersensitivity. Based in these considerations, our efforts have been to purify and identify PIII components that are responsible for the modulation of granuloma formation, and to provide protective immunity in schistosomiasis. Therefore, an important strategy for improving vaccine efficacy is to define mechanisms of immunity operating in a given vaccination protocol and attempt to enhance the response for young parasite forms and decrease the granulomatous hypersensitivity against eggs trapped in host tissue.

The role of P-24 and P-35 as protective antigens was supported by the immunization of mice. Three successive immunizations with these antigens, in the presence of $C$. parvum and $\mathrm{Al}(\mathrm{OH})_{3}$, gave a high level of resistance to a subsequent cercarial challenge. The parasite burden obtained by liver perfusion was reduced to $55 \%$ and $67 \%$, respectively. Spleen cells from these mice exhibited a strong proliferative responses to $\mathrm{P}-24, \mathrm{P}-35$ and P-97, and even to PIII. It appears that PIII components are responsible for inducing heterogeneity in cell-mediated responses. Several groups have demonstrated the potential vaccinating effect of different S. mansoni antigens and obtained several levels of protection (Harn et al. 1984, Smith \& Clegg 1985, Sher et al. 1986).

Data presented here clearly demonstrate that PIII and its purified components P-24 and P-35 might be of help in the development of a vaccine, which could reduce worm burden and contribute to inhibit the pathology resulting from egg deposition.

A recent report on vaccines against schistosomiasis (Butterworth 1992) showed that certain aspects of host immune response were important on the evaluation of the usefulness of schistosomiasis vaccines. When vaccines were tried in mice, the final result was always that a few organisms from challenge infection developed into adult worms. Because adult worms do not divide, any candidate antigen capable of reducing the number of worms and the granuloma size in human would be beneficial (Colley \& Colley 1989, Butterworth 1992).

\section{REFERENCES}

Andrade ZA, Warren KS 1964. Mild prolonged schistosomiasis in mice: alterations in host response with time and the development of portal fibrosis. Trans $R$ Soc Trop Med Hyg 58: 53-57.

Bergquist R 1990. Prospects of vaccination against schistosomiasis. Scand J Infec Dis 76: 60-71.

Boulanger D, Reid GD, Sturrouk RF, Wolowezuk I, Balloul JM, Grezel D, Pieree RJ, Oticno MF, Guerret S, Grimaud JA, Buterworth AE, Capron A 1991. Immunization of mice and baboons with the recombinant Sm28GTS affects both worm viability and fecundity after experimental infection with Schistosoma mansoni. Parasite Immunol 13:473-478.

Butterworth AE 1992. Vaccines against schistosomiasis: where do we stand? Trans R Soc Trop Med Hyg 86: $1-2$.

Carter CE, Colley DG 1979. Partial purification of Schistosoma mansoni soluble egg antigen with Com Asepharose chromatography. J Immunol 122: 220422099.

Cheever AM, Finkelman FD, Caspar P, Hieny S, Macedonia JG, Sher A 1992. Treatment with antiIL-2 antibodies reduces hepatic pathology and eosinophilia in Schistosoma mansoni infected mice while selectively inhibiting T cell IL-5 production. $J$ Immunol 148: 3244-3248.

Colley DG, Colley DM 1989. Protective immunity and vaccines to schistosomiasis. Parasitol Today 5: 350354.

Dissous C, Grzych J, Capron A 1982. Schistosoma mansoni surface antigen defined by monoclonal IgG2a. J Immunol 129: 2232-2234.

Goding JW 1986. Monoclonal Antibodies: Principles and Pratice, 2nd ed., Academic Press, London, 315 pp.

Goes AM, Gazzinelli G, Rocha R, Katz n, Doughty BL, 1991. Granulomatous hypersensitivity to Schistosoma mansoni egg antigens in human schistosomiasis. III. In vitro granuloma modulation induced by immune complexes. Am J Trop Med Hyg 4: 434443.

Goes AM, Rocha RS, Gazzinelli G, Doughty BL 1989. Production and characterization of human monoclonal antibodies against Schistosoma mansoni. Parasite Immunol 11: 695-711.

Harn DA, Mitsuyama M, David JR 1984. Schistosoma mansoni: anti-egg monoclonal antibodies protect against cercarial challenge in vivo. J Exp Med 159: 1371-1387.

Harn DA, Danko K, Quinn JJ, Stadecker MJ 1989. Schistosoma mansoni: the host immune response egg antigens. I. Partial characterization of cellular and hummoral responses to $\mathrm{pI}$ fractions of soluble egg antigens. J Immunol 142: 2061-2066.

Harn DA, Mitsuyana M, Huguenel ED, Oligino L, David JR 1985. Identification by monoclonal antibody of a major (28kDa) surface membrane antigen of Schistosoma mansoni. Mol Biochl Parasitol 16: 345-354.

Hirata M, Takushima M, Kage M, Fukuma T 1993. Comparative analysis of hepatic, pulmonary, and intestinal granuloma formation around freshly laid Schistosoma japonicum eggs in mice. Parasitol Res 79: 345-354.

Hirsch C, Goes AM 1996. Characterization of fraction- 
ated Schistosoma mansoni soluble adult worm antigens that elicit human cell proliferation and granuloma formation in vitro. Parasitology 112: 529-535.

Hirsch C, Zouain CS, Alves JB, Goes AM 1997. Induction of protective immunity and modulation of granulomatous hypersensitivity in mice using PIII, an anionic fraction of Schistosoma mansoni adult worm. Parasitology 115: 21-28.

Hsu SL, Hsu HF, Svestka KW, Clark W 1986. Vaccination against schistosomiasis in mice with killed schistosomula without adjuvant. Proc Soc Exp Biol Med 181: 454-461.

Jeffs AS, Hagan P, Allen R, Correa-Oliveira R, Smithers R, Simpson A 1991. Molecular cloning and characterization of the 22-kDa adult Schistosoma mansoni antigen recognized by antibodies from mice protectively vaccinated with isolated tegumental surface membranes. Mol Biochem Parasitol 46: 159-168.

Laemmli UK 1970. Cleavage of structural proteins during the assembly of the head of bacteriophage T4. Nature 227: 680-683.

Lukacs NW, Boros DL 1992. Utilization of fractionated soluble egg antigens reveals selectively modulated granulomatous and lymphokine responses during murine schistosomiasis mansoni. Infect Immun 60: 3209-3216.

Payares G, Kelly C, Smithers SR, Evans WH 1985. Evidence that the 32,38 and $20 \mathrm{~K}$ surface antigens of schistosomula and schistosomes are related proteins. Mol Bioch Parasitol 17: 115-130.

Rezende AS, Gollob K, Correa-Oliveira R, Goes AM
1998. Down modulation of MHC surface molecules on B cells by suppressive immune complexed obtained from chronic intestinal schistosomiasis patients. Immunol Letters 62: 67-73.

Sher A, Pearce E, Hieny S, James S 1986. Induction of protective immunity against Schistosoma mansoni by a nonliving vaccine. IV. Fractionation and antigenic properties of a soluble adult worm; immunoprophylactic activity. J Immunol 136: 38783884.

Smith MA, Clegg JA 1985. Vaccination against Schistosoma mansoni with purified surface antigens. Science 277: 535-538.

Smithers SR, Terry RJ 1965. The infection of laboratory host with cercariae of Schistosoma mansoni and the recovery of adult worms. Parasitology 55: 565570.

Towbin HT, Stackelin T, Gordon J 1979. Eletrophoretic transfer of protein from polyacrylamide gels to nitrocellulose sheets: procedure and some apllications. Proc Nat Acad Sci USA 76: 4350-4355.

Warren KS, Domingo EO, Cowan RBT 1967. Granuloma formation around schistosome eggs as a manifestation of delayed hypersensitivity. Amer J Pathol 51: 735-743.

Wynn TA, Eltoum I, Oswald IP, Cheever AW, Sher A 1994. IL-12 endogenously regulates granuloma formation induced by eggs of Schistosoma mansoni and acts exogeneously to both inhibit and prophylactically immunize against egg pathologgy. J Exper Med 179: 155-161. 